\title{
Computer Aided Teaching for Material Mechanics
}

\author{
Yuanzhu Zhang ${ }^{1, a^{*}}$, Jiabao Li ${ }^{1, b}$ and Qigang Guo ${ }^{2, c}$ \\ 'Zhejiang University City College, Hangzhou, China \\ ${ }^{2}$ Zhejiang University, Hangzhou, China \\ azhangyz@zucc.edu.cn, b1098180429@qq.com, czjguogigang@126.com
}

\begin{abstract}
Keywords: Mechanics of Materials, Virtual Interactive Teaching, Computer-aided analysis.
\end{abstract}
\begin{abstract}
According to the characteristics and teaching status of Material Mechanics course, a computer aided teaching software including 12 typical examples based on ANSYS, MATLAB and JAVA was designed. The software has the characteristics of visualization, interactivity and comprehensiveness, which can be applied in theory and practice teaching. Teaching practice proves that it is helpful to inspire students' learning interest and improve learning effect.
\end{abstract}

\section{Introduction}

Material Mechanics is a core course of civil engineering, which plays an important role in the engineering training. The course teaches students basic concepts and methods of strength, stiffness and stability, meanwhile it trains modeling ability and practice ability for students. Compared with research-oriented university, our students are relatively weak in mathematical basis, and mainly engaged in front-line work after graduation. When they face the abstract concepts and complex mathematical deduction and calculation of Material Mechanics course, some students feel difficult to study, and then gradually lose their motivation and effort to learn, which results in their lack of mechanic concepts and principles. Hence, how to make students firmly grasp professional knowledge, basic skills and practical ability, and to be helpful for following study of specialized courses is a problem.

The 21 st century is the information age, and computer technology is developing rapidly. Hence it provides new development for Material Mechanics course teaching. Many engineering colleges have carried out teaching reforming in China [1-2]. With the help of numerical analysis and animation techniques, computer-aided teaching could help students to understand the deformation and failure process of bars under different conditions, and inspire students' learning interest and improve learning effect.

\section{Design of virtual interactive teaching software}

\subsection{Design ideas}

The flow chart of the Aided Teaching software is shown in Fig.1. First, we select typical examples of each chapter, hen, the reaction force, internal force, stress, strain and deformation of bars are correspondingly calculated by MATLAB based on the Material Mechanics analytic method, due to MATLAB has powerful numerical calculation and simple programming language. After that, ANSYS is used to numerical simulation after building model, meshing, setting constraints and loading, then export the animation of deformation and stress of the model during loading process. Java can develop a friendly graphical user interface. In this study, the modified interactive parameter interface (Fig.2) is produced by Java compiler [3]. The interactive system consists of 12 finite element examples: axial tension and compression, torsion of circular shaft, bending, stretching and bending combination, oblique and bending combination, bending and torsion combination and compressive bar stability. Each example contains three modules. Selecting an example, animation demonstration from ANSYS numerical analysis can directly show the whole loading and deformation process, at the same time the theoretical solution can be invoked by MATLAB program. In addition, the models can be calculated by calling the command flow of ANSYS. 


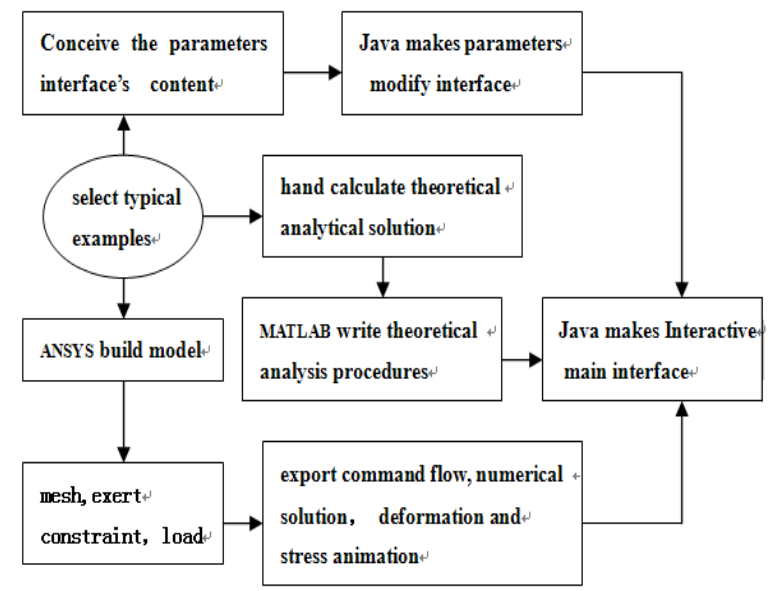

Fig. 1. The flow Chart

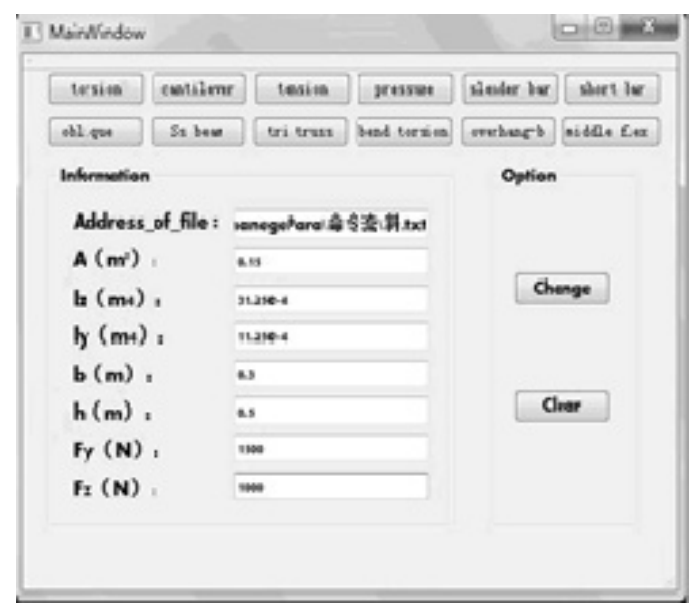

Fig. 2. The interactive system

\subsection{Design features}

Our computer-aided analysis software has characteristics of visualization and interaction. The powerful numerical analysis and graphical display can not only make students to easily understand and grasp the abstract concept, but also help students to improve their ability of imagination and thinking. Moreover, it can help students get rid of time and space constraints so as to practice repeatedly. Meanwhile, it can solve the impact of teaching time deficiency. As a result, it can inspire the interest and improve the thinking capability of students in learning, then improve the study effect of mechanical materials.

This paper takes the stress and deformation analysis of cantilever beam as an example to demonstrate the whole process.

A cantilever beam ( length $2.5 \mathrm{~m}$, height $0.6 \mathrm{~m}$ and width $0.3 \mathrm{~m}$ ) is loaded with a concentrated force of $1 \mathrm{KN}$ shown in Figure 3. Firstly, the corresponding numerical solution and stress animation (Fig.4) were obtained by ANSYS simulation. Then export the command file. After that, the user can modify the command file with the help of the parameter modification interface to determine that the ANSYS software is called to calculate the numerical solution of different models. At the same time, the MATLAB program is used to calculate the theoretical analytic solution for comparison. 


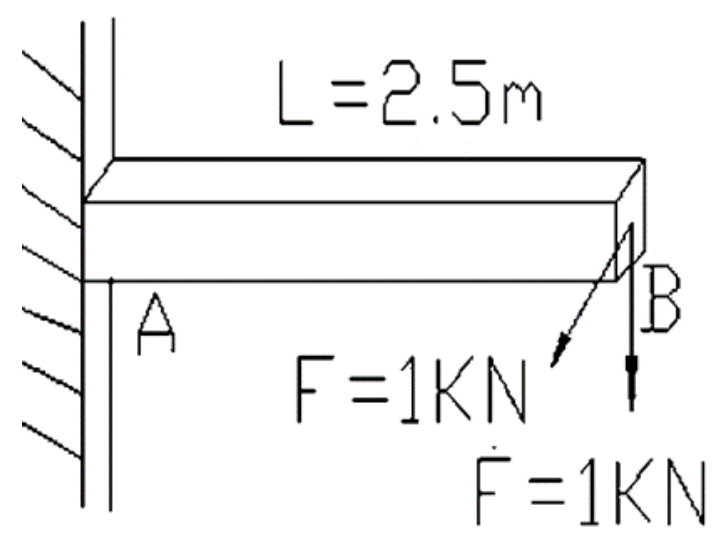

Fig. 3. Cantilever oblique bending model

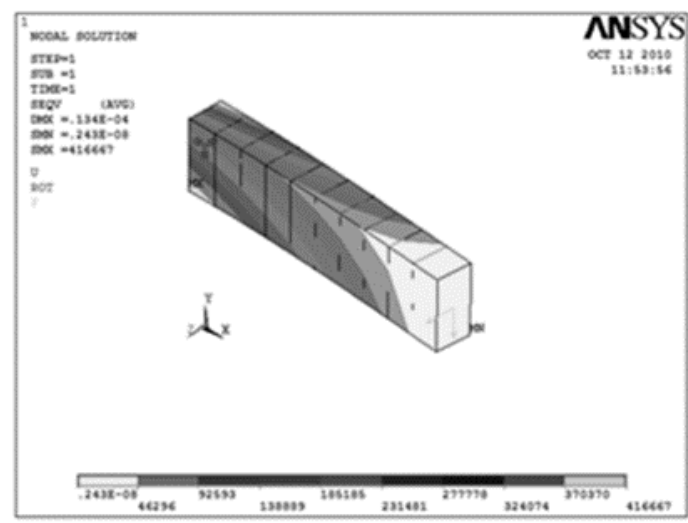

Fig.4. Stress animation

\section{The application of virtual interactive teaching software}

Up to now, the virtual teaching has been successfully applied in Material Mechanics for civil engineering students. In the traditional mode of teaching, due to the characteristics of Material Mechanics course and students, some students acquire knowledge by rote learning before test and easily forget after exam. Compared with the final test in the past, it's proved that the software can promote the learning effects of theoretical teaching and experimental teaching. In teaching, teachers can use the software to play animations and visual display the results of numerical analysis, which can help students to have a deeper understanding of the abstract concepts and inspire their interest in learning. Meanwhile, by comparing the theoretical solutions from MATLAB and numerical solutions from ANSYS, students have a more intuitive and in-depth understanding of structural deformation, which is helpful to solve complex problems and have a more comprehensive understanding of knowledge. In addition, students also can enhance their numerical calculation ability by means of software, which is helpful to the following professional courses study. Moreover, the software provides a learning platform for students to explore after class. After the software is improved, it can also be opened to other schools to benefit more students.

\section{Conclusion}

We designed a computer aided teaching for Material Mechanics based on MATLAB, ANSIS and JAVA software, which can demonstrate loading animation to help students understand the development of stress and deformation. In addition, it not only improves teaching in classrooms, but also provides practice for students after classes. Teaching practice shows that it is helpful to improve students' learning interest and learning effect. 


\section{References}

[1] Y. YONG, Talking about the organic integration of ANSYS and the course of Material Mechanics, Sci/Tech Information Development and Economy, Vol.20, pp.216-218 ,2005.

[2] W.T. Wang, W. Li, MATLAB application in the teaching of Mechanics of Materials, Journal of Henan Mechanical and Electrical Engineering College, Vol.18, pp.90-91 ,2010.

[3] Y.Q. SHEN, J. Wang, W.Q. LING. Second development technology of ANSYS based on PDAE. Manufacturing Information Engineering of China,vol.23, pp.28-34,2010. 